and Urodela are known, mostly from the Cainozoic era, but until the account by Estes and Wake (see page 228 of this issue of Nature) no authentic caecilian fossil was known. The single, but quite diagnostic, vertebra described in their communication is the first stage in the filling of an important gap in the fossil record. The specimen comes from the Palaeocene of Brazil. The time, at the beginning of the Cainozoic, is surprisingly early and the locality, as the authors point out, may be at odds with the present distribution of genera within the order.

Estes and Wake conclude that their fossil vertebra resembles those of an extant African genus more than it does the vertebrae of any New World form. This leads them to some rather bold speculations on the former distribution of caecilians. Their single vertebra is, however, separated by a time gap of some sixty million years from all other known members of the group, so that even the most tentative conclusions about its relationships within the caecilians seem premature.

The discovery of more skeletal material of this or any other fossil caecilian is eagerly awaited. Should the authors' speculations prove correct it would be demonstrated that essentially modern caecilians had evolved and radiated before the dawn of the Cainozoic Era. This would place the time of origin of the group well back into the Mesozoic, paralleling what is known of the evolutionary history of the other two extant amphibian orders.

The earliest known fossil urodele comes from the Upper Jurassic of the United States, and the earliest fully evolved frog from the Lower Jurassic of Argentina. Before that time the evolutionary history of all three groups is obscure. It is generally but not universally agreed that a small fossil amphibian Triadobatrachus (long known as "Protobatrachus") from the early Triassic is related to frog ancestry. Earlier specimens, isolated vertebrae from the American Permian and tracks looking like the footprints of a frog from the Permian of South Africa, have been tentatively cited as remains of Lissamphibia (the three living orders) but this has not been generally accepted.

The origin of the Lissamphibia has thus been for many years a rich field for inadequately supported theory and sometimes acrimonious argument. Until relatively recently it was frequently the practice to trace the anurans and the urodeles respectively back to different Palaeozoic ancestral groups. The caecilians were usually ignored or brigaded with the urodeles by default This separation is retained by Jarvik, who traces the two major groups back to two principal divisions of the Devonian rhipidistian fishes. This work, although anatomically meticulous, is not generally accepted outside Sweden, for no intermediate forms are proffered to bridge the gap of $400 \mathrm{mil}$ lion years between the Devonian and the present.

Within the past decade the chances of producing a valid hypothesis of the origin of the Lissamphibia have improved. The term Lissamphibia was revived by Parsons and Williams in 1962 to distinguish the extant orders from the totally extinct fossil orders, which had disappeared by the end of the Triassic. It was pointed out that the extant groups were united by a number of specializations, notably cutaneous respiration, and particularly by the key character of pedicellate teeth, in which the crown and root are separated by a region of connective tissue. This type of tooth is otherwise unknown in tetrapods or any related fish group.

More recently Bolt has described a small lower Permian labyrinthodont amphibian with pedicellate teeth and other characters, particularly the structure of the vertebrae, suggestive of Lissamphibian ancestry. It is to be hoped that the caecilian vertebra described in Nature this week will be the first of many discoveries of fossil members of that order, so that concepts of Lissamphibian ancestry will take due account of the third and least known group of living Amphibia.-From our Vertebrate Palaeontology Correspondent.

\section{SOLID STATE}

\section{Problems with Caesium}

from a Correspondent

THE present theoretical framework for the description of the electronic structure of simple metals seems inadequate to describe a new feature in the high frequency absorption of the alkali metal caesium. This is the conclusion of a careful analysis by $J$. Hermanson of Montana State University (Phys. Rev. $B$, 6, 400; 1972).

From some points of view the alkali metals should be the simplest metallic systems, and most of their electronic properties are described very well by an independent free electron model in which the effects of the ionic lattice are extremely weak. The predictability of single-particle effects in these materials has made them a favourite hunting ground for the elusive manyelectron effects caused by the strong Coulomb interaction that occurs between electrons.

Various theoreticians have suggested that such effects may occur in the optical absorption of metals for photon energies greater than the plasmon energy, and the simplicity of the alkali metals gives the prospect of disentangling manyelectron effects from the single-particle effects that produce the optical absorption at frequencies less than the plasma frequency. These are, first, Drude absorption, which is an intraband process involving the emission or absorption of a phonon, and, second, interband absorption. The former dominates at low photon energies $(\ll 1 \mathrm{eV})$ and then falls off rapidly, while in caesium the interband absorption has a threshold just below $1 \mathrm{eV}$. Previous theoretical work had suggested that excitation of collective modes makes an important contribution at frequencies greater than the plasma frequency, and the recent experimental data of Whang et al. (Phys. Rev. Lett., 25, 646 ; 1971) show a prominent high frequency absorption peak at about $5 \mathrm{eV}$ which does not seem to lend itself to interpretation as an interband transition. This was originally interpreted in terms of a collective effect with a threshold at $\hbar \omega_{\mathrm{p}}+\hbar \omega_{0}$, where $\omega_{\mathrm{p}}$ is the plasma frequency and

\title{
Transfer of Phage Receptor Sites
}

A METHOD for transferring the lipopolysaccharide receptor sites for coliphage U3 from phage-sensitive cells to spheroplasts of phage-resistant cells is reported in Nature New Biology next week (September 27) by Watson and Paigen. Coliphage U3 adsorbs only to Escherichia coli $\mathrm{K} 12$ cells that have incorporated galactose into lipopolysaccharides of their cell walls and as a result strains of $E$. coli K12 carrying a gal deletion, for example, the strain SA242, resist infection by this phage. When, however, spheroplasts of SA242 cells are exposed to cell wall lipopolysaccharide extracted by phenol from sensitive $\mathrm{K} 12$ cells about 1 per cent of the recipient spheroplasts can subsequently be infected by U3 phage par- ticles in the presence of DNAase, which eliminates infection by naked U3 DNA.

This attachment of the lipopolysaccharides including U3 receptors to spheroplasts takes place in the presence of sodium cyanide, so it does not require energy or de novo synthesis of cell wall materials by the recipients. Moreover the acquired receptor sites have a comparatively short half-life, for after about 60 min metabolizing recipient spheroplasts begin to lose their sensitivity to U3. As Watson and Paigen point out it should be possible to transfer receptor sites for other phages in a similar way, and this approach may open new avenues to the investigators of the function and biosynthesis of bacterial cell walls. 